ORIGINAL ARTICLE

\title{
Clinical Characteristics, Seasonal Variation, Outcome and Disturbance of Taste and Smell in Cases of COVID-19
}

Sumera Akram¹, Muhammad Ahmed Khan ${ }^{2}$, Saeed Akhtar Khan Khattak ${ }^{3}$, Muhammad Ameen Khan ${ }^{4}$, Muhammad Sajid Hussain ${ }^{5}$, Bakhtawar Mustajab ${ }^{6}$

\section{ABSTRACT}

Objective: To assess the various clinical characteristics, seasonal variation, outcome and disturbance of taste (aguesia) and smell (anosmia) in cases of COVID-19.

Study Design: Cross sectional study.

Place and Duration of Study: The study was carried out in the Department of COVID-19 at Combined Military Hospital (CMH), Mardan from March 2020 to February 2021.

Materials and Methods: Suspected case of corona virus disease-2019 (COVID-19) admitted and managed at CMH Mardan from March 2020 to February 2021 were included in the study and their nasopharyngeal swabs were sent for COVID-19 polymerase chain reaction (PCR) test. Only those clinically suspected cases with positive PCR for COVID-19 were considered as cases of COVID-19. Demographic and clinical data including gender, age, result of COVID-19 PCR test, symptoms, severity of disease, body system affected with COVID and outcome, were recorded and entered in SPSS 21 . Chi square was used to analyze qualitative variables and T test was used for quantitative variables. $P$ value less than 0.05 was considered significant.

Results: The reported clinically suspected cases of COVID-19 were 1552. Positive PCR test for COVID-19 were $221(14.2 \%)$ with mean age $37.53 \pm 11.05$. The highest number of COVID-19 cases were seen from May 2020 to July 2020. The positivity ratio of COVID-19 was highest during May 2020 (29.9\%). Majority of COVID-19 cases were asymptomatic (45.7\%) and only ten cases died of COVID-19, i.e. mortality was 4.5\%.Out of 221 COVID-19 patients, $38.5 \%$ cases had olfactory and taste dysfunction.

Conclusion: COVID-19 surged during the months of May to July 2020 followed by a downhill course. Majority of COVID-19 cases were asymptomatic. Respiratory system of body was most common system involved followed by gastrointestinal and combination of respiratory and gastrointestinal system. Olfactory and taste dysfunction (anosmia and aguesia) was seen commonly in COVID-19 patients.

Key Words: Ageusia, Anosmia, COVID-19, Nasopharyngeal, Olfactory, Outcome, Smell, Taste.

How to cite this: Akram S, Khan MA, Khattak SAK, Khan MA, Hussain MS, Mustajab B. Clinical Characteristics, Seasonal Variation, Outcome and Disturbance of Taste \& Smell in Cases of COVID-19. Life and Science. 2021; 2(4): 155-159. doi: http://doi.org/10.37185/LnS.1.1.193

This is an Open Access article distributed under the terms of the Creative Commons Attribution License (http://creativecommons.org/licenses/by/4.0), which permits unrestricted use, distribution, and reproduction in any medium, provided the original work is properly cited.

\section{Introduction}

On December $29^{\text {th }} 2019$, patients were presented in a

${ }^{1}$ Department of Pediatrics/ENT ${ }^{2} /$ Medicine $^{5}$

Combined Military Hospital (CMH), Zhob

${ }^{3}$ Department of Pathology/Medicine $e^{4,6}$

Combined Military Hospital (CMH), Zhob

Correspondence:

Dr. Sumera Akram

Department of Pediatrics

District Headquarter Hospital (DHQ)q, Zhob

E-mail: sumera_ak@yahoo.com

Funding Source: NIL; Conflict of Interest: NIL

Received: Mar 20, 2021; Revised: Jul 10, 2021

Accepted: Aug 27. 2021

155 local hospital of Hubei province of China with pneumonia from unknown pathogen working in a sea food store which was later identified as SARSCov2 and the condition was named as corona virus disease 2019 (COVID-19). The clinical symptoms were fever, lethargy, cough, flu, stuffed nose, myalgias. Based upon the clinical presentation of patients and severity of symptoms the COVID-19 was further categorized into asymptomatic, mild, moderate, severe and critical state. Asymptomatic presents with absence of any symptoms but serological positive result for COVID-19. Mild disease 
comprises sore throat, fever, myalgias. Moderate disease had patients with respiratory symptoms including evidence of pneumonia on radiography, while in severe disease patients present with respiratory distress \& dropping oxygen saturation. Critical form had patients with respiratory and end organ failure and in need of mechanical ventilator. ${ }^{1}$

This virus infects all age groups but has serious implications in individuals at the extremes of age i.e. neonates, children, elderly and also patients with chronic diseases such as cardiovascular, diabetics, stroke and cancer patients on chemotherapy. It runs a different course in every patient depending upon the immune status and it has been deducted that people with low immunity are more likely to suffer extreme complications including death. ${ }^{2}$ Complete blood count show reduced white blood cells, lymphopenia and no response to antibiotics for the respiratory symptoms. Apart from the clinical suspicion the diagnosis of COVID-19 is based upon the real time PCR of the oral, nasal swabs and respiratory secretions followed by gene sequencing. CT chest shows ground glass appearance and pulmonary infiltrates. $^{3}$

Like any other respiratory disease the virus is spread through droplets and respiratory secretions disseminated into the air through cough or sneeze. In addition to being an air borne infection, it also spread through fomite or direct contact with the affected person (with or without any manifestations of the disease). Social distancing, regular hand washing, isolation have proven to reduce the spread of the infection. The use of personal protective equipment, surgical masks and gloves for the health care professionals should be available. ${ }^{4,5}$

World Health organization announced COVID-19 outbreak as sixth public health emergency of international concern on $30^{\text {th }}$ January 2020 and later as pandemic on $11^{\text {th }}$ March $2020 .^{6}$ First case of COVID-19 was reported in Pakistan in February 2020, when an individual travelled back after visiting Iran. In Pakistan, first death of COVID-19 was reported in March 2020. ${ }^{8}$ Till date, total 581,365 confirmed cases of COVID-19 have been reported with 12896 deaths due to this illness. ${ }^{9}$

Efforts are being made all over the world to find cure for the disease and prepare vaccine with 100 percent efficacy to put an end to this unprecedented epidemic of history. Current study was carried out to study clinical characteristics, seasonal variation, outcome and associated taste \& smell disturbance of admitted cases at Mardan $\mathrm{CMH}$, to understand epidemiology of this new unprecedented epidemic.

\section{Materials and Methods}

The study was carried out in the Department of COVID-19 at CMH, Mardan from March 2020 to Feburary 2021. Ethical Review Board of CMH Mardan granted permission and consent was taken from all the eligible participants.

\section{Inclusion criteria:}

1. Cases with fever, cough, sore throat, myalgias, shortness of breath, loss of sense of smell or taste, vomiting, diarrhea, headache (any combination of these) whose Nasopharyngeal swabs PCR was positive for COVID-19.

2. Cases in direct contact with COVID-19 patients whose PCR was positive for COVID-19.

3. Cases who had recent travel history.

4. Asymptomatic cases whose PCR was positive for COVID-19.

\section{Exclusion Criteria:}

1. All the cases with fever, sore throat, cough, myalgias, loss of taste or smell, vomiting, diarrhea etc whose PCR was negative for COVID19 were excluded.

2. The cases who did not consent for inclusion in the subject study were also excluded.

All the data including gender, age, result of COVID-19 PCR test, symptoms, type of system involved (asymptomatic, respiratory, gastrointestinal, combined respiratory \& gastrointestinal system, severity of disease (asymptomatic, mild, moderate, severe, critical) outcome of case i.e death, were recorded and entered in SPSS 21 on monthly basis. Severity of disease was categorized from asymptomatic to critical depending on condition of the patient. Patients with symptoms of fever, cough, sore throat, headache without lung involvement (normal chest X-ray and CT scan) were classified as "mild disease". The individuals who had pneumonia and irritability, without any distress, were termed "moderate disease". The cases in whom, lung involvement was more than $50 \%$ with dyspnea, distress and hypoxemia (Oxygen saturation $<94 \%)$ were classified as "severe disease". In "Critical 
disease", the cases had respiratory distress syndrome, septic shock, cytokine release syndrome or multi-organ failure. Chi square was used to analyze qualitative variables (gender, type of disease). $P$ value less than 0.05 was considered significant.

\section{Results}

There were total 1552 cases suspected of covid-19 at our hospital from March 2020 to February 2021 (01 year). Their nasopharyngeal swab was taken and sent for COVID PCR to the laboratory under full protocol. Sterile swab was inserted along the floor of nose till nasopahrynx and rotated several times against walls of nasopharynx. The swab was then removed carefully and placed in the transport tube which was sent to laboratory immediately. Among 1552 suspected cases of COVID-19, there were 841 $(54.2 \%)$ males and 710 (45.7\%) females. Out of them, 1331 (85.6\%) results came negative for COVID-19 PCR and rest 221 (14.2\%) were positive Thepositivity ratio of COVID-19 PCR result was $14.2 \%$. Age range was 10 to 76 years with mean age $35.94 \pm 11.43$ years. Age range of PCR positive COVID-19 cases was from 15 to 70 years with mean age $37.53 \pm 11.05$. The age range of COVID- 19 negative cases was 10 to76 years with mean age $35.68 \pm 11.48$ years. First suspected case of COVID-19 was reported in March 2020. Month wise number of cases suspected of COVID and their COVID polymerase chain reaction

\begin{tabular}{clccc}
\hline \multicolumn{4}{l}{$\begin{array}{l}\text { Table 1: Month wise Prevalence/percent positive rate of COVID -19 } \\
(\boldsymbol{P}=\mathbf{0 . 0 0 0 )}\end{array}$} \\
\hline S/No & Month & $\begin{array}{l}\text { Suspected } \\
\text { COVID cases } \\
\text { (n) }\end{array}$ & $\begin{array}{l}\text { COVID PCR } \\
\text { Negative } \\
\text { cases(n) }\end{array}$ & $\begin{array}{l}\text { COVID PCR } \\
\text { Positive cases } \\
\text { (n) }\end{array}$ \\
1 & March 2020 & $14(0.9 \%)$ & $13(0.9 \%)$ & $1(0.5 \%)$ \\
2 & April 2020 & $63(4.1 \%)$ & $43(3.2 \%)$ & $20(9 \%)$ \\
3 & May 2020 & $264(17 \%)$ & $198(14.9 \%)$ & $66(29.9 \%)$ \\
4 & June 2020 & $97(6.2 \%)$ & $73(5.5 \%)$ & $24(10.6 \%)$ \\
5 & July 2020 & $99(4.1 \%)$ & $69(5.2 \%)$ & $30(13.6 \%)$ \\
6 & August 2020 & $64(4.1 \%)$ & $59(4.4 \%)$ & $5(2.3 \%)$ \\
7 & September 2020 & $131(8.4 \%)$ & $124(9.3 \%)$ & $7(3.2 \%)$ \\
8 & October 2020 & $106(6.8 \%)$ & $95(7.1 \%)$ & $11(4.9 \%)$ \\
9 & Nov 2020 & $162(10.4 \%)$ & $148(11.1 \%)$ & $14(6.3 \%)$ \\
10 & Dec 2020 & $177(11.4 \%)$ & $165(12.4 \%)$ & $12(5.4 \%)$ \\
11 & Jan 2021 & $214(13.8 \%)$ & $195(14.6 \%)$ & $19(8.6 \%)$ \\
12 & Feb 2021 & $161(10.3 \%)$ & $149(11.2 \%)$ & $12(5.4 \%)$ \\
Total & & 1552 & 1331 & 221 \\
\hline
\end{tabular}

(PCR) results and Prevalence/Percent positivity rate of COVID-19 cases are shown in Table 1. The highest number of COVID-19 cases were seen from May 2020 to July 2020. Prevalence/Positivity rate was highest during May 2020 (29.9\%) followed by July 2020 (13.6\%) and June 2020 (10.6\%).

The study showed, majority of COVID-19 cases were asymptomatic $n=101$ (45.7\%). Out of symptomatic individuals80 (36.2\%) had respiratory system, 15 (6.8\%) had gastrointestinal system and 25 (14.2\%) had combination of respiratory and gastrointestinal system involvement. (Table 2 )

\begin{tabular}{|c|c|c|c|}
\hline \multirow[b]{2}{*}{ Type of system } & \multicolumn{2}{|c|}{ Cases } & \multirow[b]{2}{*}{ Total } \\
\hline & $\begin{array}{l}\text { COVID PCR } \\
\text { Negative }\end{array}$ & $\begin{array}{l}\text { COVID PCR } \\
\text { Positive }\end{array}$ & \\
\hline Asymptomatic & 782(58.8\%) & 101(45.7\%) & $883(56.9 \%)$ \\
\hline Respiratory & 425(31.9\%) & $80(36.2 \%)$ & $505(32.5 \%)$ \\
\hline Gastrointestinal & $111(8.3 \%)$ & $15(6.8 \%)$ & $126(8.1 \%)$ \\
\hline $\begin{array}{l}\text { Combined } \\
\text { respiratory and } \\
\text { gastrointestinal } \\
\text { system }\end{array}$ & $13(0.9 \%)$ & $25(11.3 \%)$ & $38(2.4 \%)$ \\
\hline Total & 1331 (85.8\%) & 221(14.2\%) & 1552 \\
\hline
\end{tabular}

The results showedthat in severe-critical categories, 10 died of COVID-19, i.e mortality was $4.5 \%$ of COVID-cases (Table 3).

Table 3: Severity of COVID-19 $(P=0.000)$

\begin{tabular}{lcc}
\hline Severity of Disease & Total & \\
(COVID-19) & COVID PCR Positive & $P$-value \\
Asymptomatic & $101(45.7 \%)$ & \\
Mild & $96(43.4 \%)$ & \\
Moderate & $11(5 \%)$ & \\
Severe & $4(1.8 \%)$ & 0.000 \\
Critical & $9(4.1 \%)$ & \\
Total & $221(14.2 \%)$ & \\
\hline
\end{tabular}

The number of cases without disturbance of taste or smell were 136 (61.5\%). Cases with combined anosmia (disturbance of smell) and aguesia (disturbance of taste) were 32 (14.5\%)only with anosmia $38(17.2 \%)$ and only aguesiawere $15(6.8 \%)$ (Figure 1).

Clinical Characteristics, Seasonal Variation, Anosmia and Aguesia in COVID-19.

\section{Discussion}

In current research, 221 confirmed cases of COVID19 were reported from March 2020 to February 2021 
n Cases without Anosmia and Ageusia = Anosmia = Anosmia \& Ageusia = Ageusia

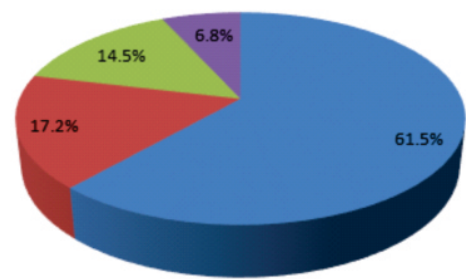

Fig 1: Frequency of olfactory and taste dysfunction

First case of corona virus was admitted during March 2020 and cases increased gradually over the next months. We saw that maximum numbers of coronavirus patients reported in May. Majority of cases were reported from May 2020 to July 2020. This surge of cases in our hospital coincided with peak/surge of cases in the country, during same months. ${ }^{10}$ COVID-19 cases hiked from May to July 2020 with downhill course during remainder of year, followed by another surge at the end of year 2020. The downhill course was possibly due to government lockdowns of cities, social distancing and weather change. The individuals, who died of COVID-19, all had co-morbid conditions. Same has been seen worldwide. ${ }^{11,12}$ Hypertension, diabetes mellitus, obesity, immunocompromised conditions (carcinomas), chronic kidney disease, chronic obstructive pulmonary diseases are strongly associated co-morbid conditions with severity and mortality of COVID-19. ${ }^{11}$ Majority of COVID-19 cases were asymptomatic in our study i.e $45.7 \%$ followed by mild disease (43.4\%). He J et al. showed that $15.6 \%$ of COVID-19 cases were asymptomatic which is much less than shown in our study. ${ }^{13} \mathrm{He} \mathrm{J}$ et al. further found that ratio of asymptomatic cases was highest in children than any age group. In our study, we had no pediatric case with positive PCR result. Peterson I and co-workers had reported asymptomatic COVID-19 infection in $76.5 \%$ cases in their study. ${ }^{14}$ Chen J et al reported that majority of SARS CoV-2 infected individuals had mild symptoms. ${ }^{15}$ In our study, we saw respiratory involvement in $36.2 \%$, gastrointestinal system in $6.8 \%$ and combined respiratory and gastrointestinal involvement in $11.3 \%$. Ghoshal UC et al showed 85.2 $\%$ asymptomatic cases which is much higher than our study. ${ }^{16}$ Ghoshal Et al showed that 18 cases out of total $208(8.7 \%)$ had respiratory symptoms (fever, sore throat), 15 cases of total 2028 (7.2\%) had gastrointestinal symptoms (nausea, diarrhea, pain abdomen, vomiting) and 11 of 208 (5.3\%) had combination of both respiratory and gastrointestinal symptoms. He showed higher frequency of asymptomatic and lower frequency of respiratory symptoms than in our study. ${ }^{16}$

Nose is the entry point of this sinister virus. Sinonasal involvement is quite common in COVID-19 patients. Many cases present with complaints of olfactory and taste dysfunction. ${ }^{17}$ In our study, we saw $38.5 \%$ COVID-19 patients had anosmia and aguesia. It is higher than study of Lee $Y$ et al, who had reported these symptoms in approximately $15 \%$ of COVID-19 cases. ${ }^{17}$ Speth MM and co-workers have reported olfactory dysfunction in $61.2 \%$ patients of COVID-19, which is higher than our finding. ${ }^{18}$ Olfactory and taste disturbance have been reported from $19.4 \%$ to as high as $85.6 \%$ cases of COVId19. ${ }^{18,19,20}$

\section{Limitations}

The study was carried out in Combined Military Hospital Mardan, which mainly caters for personnel and families of armed forces in the area. The number of COVID-19 cases presenting in our hospital were a meager portion of cases in Mardancity and surroundings.

\section{Conclusion}

Coronavirus disease (COVID-19) pandemic has spanned more than a year. It has affected mankind in an unprecedented manner with varying severity and symptomatic distribution in different individuals. COVID-19 cases hiked from May to July 2020 with downhill course during remainder of year, followed by another surge at the end of year 2020. Majority of COVID-19 cases were asymptomatic. Respiratory system of body was most common system involved followed by gastrointestinal and combination of respiratory \& gastrointestinal system. Olfactory and taste dysfunction was seen commonly in COVID-19 patients.

\section{REFERENCES}

1. Ahmed I, Rathore FA. Neurological manifestations and complications of COVID-19: a literature review. J Clin Neuroscience. 2020; 77: 8-12.

2. Nayyar ZA, Akram S, Khan MA, Zameer F. Case report of a 3 months infant who died of COVID-19. Pak Pediatr J. 2021; 45: $245-47$. 
3. Khan MA, Khan MA. Case report of a 45 years man who succumbed to COVID-19. J Coll Physicians Surg Pakistan 2020; 30: S37-S9.

4. El Zowalaty ME, Jarhult JD. From SARS to COVID-19: A previously unknown SARS- related coronavirus (SARS-CoV2) of pandemic potential infecting humans - Call for a One Health approach, OneHealth. 2020; 9: 100124.

5. Guo YR, Cao QD, Hong ZS, Tan YY, Chen SH, Jin HJ, et al. The origin, transmission and clinical therapies on coronavirus disease 2019 (COVID-19) outbreak - an update on the status,Mil Med Res. 2020; 7: 11.

6. Abid K, Bari YA, Younas M, Javaid ST, Imran A. Progress of COVID-19 epidemic in Pakistan. Asia Pac J Pub Health 2020; 32: 154-6.

7. World Health Organization. Coronavirus Disease 2019 (COVID-19), Situation Report-80. http://www.who.int/ docs/default-source/coronaviruse/situation-reports/ 20200409-sitreps-80-covid-19.pdf?sfvrsn=1b685d64_6. Published April 9, 20.

8. Ullah R, Rana MS, Qadri M, Usman M. First COVID-19 related death in Pakistan in a patient with a travel history in Saudi Arabia. Asian Pac J Trop Med. 2020; 13: 375-7.

9. Pakistan: WHO Coronavirus Disease(COVID-19) Dashboard with Vaccination data. http://covid19.who.int/ region/emro/country/pk. [Accessed on 02 March 21].

10. Coronavirus disease Pakistan. https;//www.google.com/ search ? kgmid =/g / 11 j $2 \mathrm{cc}=\mathrm{q} I \mathrm{I} \& \mathrm{hl}=\mathrm{e} n-\mathrm{Pk} \& \mathrm{q}=$ Coronavirusandkgs $=7182 \mathrm{c} 21 \mathrm{dfd} 5 \mathrm{~d} 02 \mathrm{~d} 8 \&$ shndl $=0 \&$ source $=\mathrm{sh} / \mathrm{x} / \mathrm{kp} /$ osrpentrypoint $=\mathrm{sh} / \mathrm{x} / \mathrm{kp} /$ osrp. [Accessed on 2 March 21].

11. Harrison SL, Fazio-Eynullayeva E, Lane DA, Underhill P, Lip GYH. Comorbidities associated with mortality in 31,461 adults with COVID-19 in the United States: A federated electronic medical record analysis. PLoS Med. 2020; 17: e1003321.

12. CDC Severe outcomes among patients with coronavirus disease 2019 (COVID-19) United States, February 12-March 16, 2020. Centers for Disease Control and Prevention: MMWR. 2020; 69: 343-6.

13. He J, Guo Y, Mao R, Zhang J. Proportion of asymptomatic coronavirus disease 2019: A systematic review and metaanalysis. Journal of medical virology. 2021; 93: 820-30.

14. Peterson I, Phillip A. Three quarters of people with SARSCoV-2 infection are asymptomatic. Analysis of english household survey data. Clin Epidemiol. 2020; 12: 1039-43.

15. Chen J, Qi T, Liu L, Ling Y, Qian Z, Li T, et al. Clinical progression of patients with COVID-19 in Shanghai, China. J Infect. 2020; 80: e1-e6.

16. Ghoshal UC, Ghoshal U, Mathur A, Singh RK, Nath A, Garg A, et al. The spectrum of gastrointestinal symptoms in patients with coronavirus disease-19: Predictors, relationship with disease severity and outcome.

17. Lee $y$, Min P, Lee S, Kim SW. Prevalence and duration of acute loss of smell or taste in COVID-19 patients. sJKoream Med Sci. 2020; 36: e174.

18. Speth $M M$, Singer-Cornelius $T$, Orberli $M$, Gengler I, Brockmeier SJ, Sedaghat AR. Olfactory dysfunction and sinonasal symptomatology in COVID-19; Prevalence, severity, timing and associated characteristics. Otolaryngol Head Neck Surd 2020; 163: 114-120.

19. Baig AA, Wasay M. Covid-19 infection; loss of taste, smell and neurogenic respiratory failure. Pak J Neurological Sci 2020; $15: 1-2$

20. Leichen JR, Cheis-Estomba C, Siati DR, Horoi M, Bon SDL, Rodriguez A. Olfactory and gustatory dysfunction as clinical presentation of mild to moderate forms of coronavirus disease (COVID-19): a multicentre European study. Eur Archives Otorhinolaryngol. 2020; 277: 2251-61. 